\title{
Etnográfica
}

Revista do Centro em Rede de Investigação em

Antropologia

vol. 21 (2) | 2017

Vol. $21(2)$

\section{O programa Escola Segura: prevenção, proximidade e comunidade}

The "Safe School" program: prevention, proximity and community

\section{Afonso de Castro Bento}

\section{OpenEdition}

\section{Journals}

\section{Edição electrónica}

URL: https://journals.openedition.org/etnografica/4921

DOI: 10.4000/etnografica.4921

ISSN: 2182-2891

\section{Editora}

Centro em Rede de Investigação em Antropologia

\section{Edição impressa}

Data de publição: 1 junho 2017

Paginação: 319-339

ISSN: 0873-6561

\section{Refêrencia eletrónica}

Afonso de Castro Bento, «O programa Escola Segura: prevenção, proximidade e comunidade», Etnográfica [Online], vol. 21 (2) | 2017, posto online no dia 09 julho 2017, consultado o 10 fevereiro 2022. URL: http://journals.openedition.org/etnografica/4921 ; DOI: https://doi.org/10.4000/ etnografica. 4921

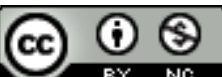

Etnográfica is licensed under a Creative Commons Attribution-NonCommercial 4.0 International License. 


\section{O programa Escola Segura: prevenção, proximidade e comunidade}

\section{Afonso de Castro Bento}

Partindo de um registo etnográfico realizado numa esquadra policial do concelho de Lisboa, este artigo pretende dar conta da forma como o programa Escola Segura está organizado e é executado pelos seus agentes no terreno. Será argumentado que atividades como ações de sensibilização ou demonstrações policiais - que têm como principal função a transmissão de normas e valores - não só desempenham um papel fundamental na definição do programa de um ponto de vista organizacional, como também constituem uma das formas mais concretas de materializar as ideias de prevenção e proximidade no contexto do policiamento português. Por sua vez, o acompanhamento da realização destas atividades revelou a importância do imaginário subjacente à ideia de comunidade para a forma como os agentes do programa Escola Segura atribuem sentido e legitimidade ao tipo de policiamento que protagonizam.

PALAVRAS-CHAVE: policiamento escolar, programa Escola Segura, prevenção, proximidade, comunidade.

The "Safe School" program: prevention, proximity and community - Based on ethnographic fieldwork carried out in a Lisbon police station, this article puts forward an analysis of the "Safe School" program, focusing on the way it is organized and carried out by its police officers. It is argued that police activities such as safety lectures or police demonstrations - which aim at transmitting norms and values - not only play a fundamental role in defining the program from the point of view of its organization, but also give shape to the notions of crime prevention and proximity in the context of Portuguese policing. Additionally, the in-depth observation of these police activities revealed the importance of the idea of community to the way through which the "Safe School" program officers assign meaning and legitimacy to the kind of policing they carry out.

KEYWORDS: school policing, "Safe School" program", prevention, proximity, community.

BENTO, Afonso de Castro (afonso.de.castro.bento@gmail.com) - Centro em Rede de Investigação em Antropologia, ISCTE - Instituto Universitário de Lisboa (CRIA/ISCTE-IUL), Portugal. 


\section{INTRODUÇÃO}

No dia 1 de junho de 2015, a propósito do Dia da Criança, a Polícia de Segurança Pública (PSP) e a Câmara Municipal de Portalegre organizaram um evento destinado a "demonstrar às crianças algumas técnicas e meios utilizados no combate à criminalidade". ${ }^{1}$ Numa foto do evento que mais tarde se revelaria controversa, surgem duas filas de crianças frente a frente. A primeira, imóvel, empunha escudos e enverga capacetes da PSP; a segunda, "vestida à civil", arremessa bolas de papel. Ao ser publicada no Facebook da Câmara Municipal de Portalegre, esta foto foi recebida com críticas de inúmeros utilizadores que denunciavam o caráter "antipedagógico", "despropositado" e "violento" da iniciativa. Nos dias seguintes, diversos meios de comunicação nacionais prolongaram e ampliaram a polémica através da produção de várias peças jornalísticas sobre o incidente.

De modo generalizado, especulou-se que a PSP tinha utilizado crianças para encenar um teatro moral que fazia opor a agentes da polícia um grupo de manifestantes desordeiros e violentos. Ao analisar os comentários daqueles que inicialmente reagiram à foto publicada no Facebook, somos levados a concluir que terá sido a utilização de crianças numa encenação simbolicamente violenta e politicamente problemática - juntamente com uma preexistente desconfiança face às instituições policiais - que terá suscitado esta controvérsia. Em resposta, a PSP redigiu uma declaração através da qual defendia que a demonstração tinha apenas o objetivo de "transmitir aos alunos comportamentos civicamente adequados", mas que, tendo em conta as repercussões do evento, "no contexto dos vários programas de proximidade e interação com a comunidade escolar [...] iria rever no imediato o contacto das crianças com os equipamentos policiais". Por sua vez, a presidente da Câmara Municipal de Portalegre pronunciou-se dizendo que:

“o mal-estar patenteado nas redes socais 'não passa de uma falsa questão, porque, na realidade não há questão’, frisando que a PSP já tinha realizado este tipo de iniciativa noutros pontos do país sem que tivesse suscitado o “mais pequeno sinal de contestação ou de crítica'”. ${ }^{2}$

1 Segundo o texto "Encenação de motim com crianças gera revolta em Portalegre", assinado por Pedro Dores e publicado no jornal Diário de Notícias, de 2 de junho de 2015 (disponível em < http://www. dn.pt/portugal/interior/encenacao-de-motim-com-criancas-gera-revolta-em-portalegre-4602096. html >).

2 Segundo notícia "Portalegre celebrou Dia da Criança com polémica simulação de motim”, assinada por Cláudia Bancaleiro e Carlos Dias e publicada no jornal Público, de 2 de junho de 2015 (disponível em <http://desporto.publico.pt/Londres2012/noticia/portalegre-celebrou-dia-da-crianca-com-simulacao-polemica-de-motim-1697644 >). 


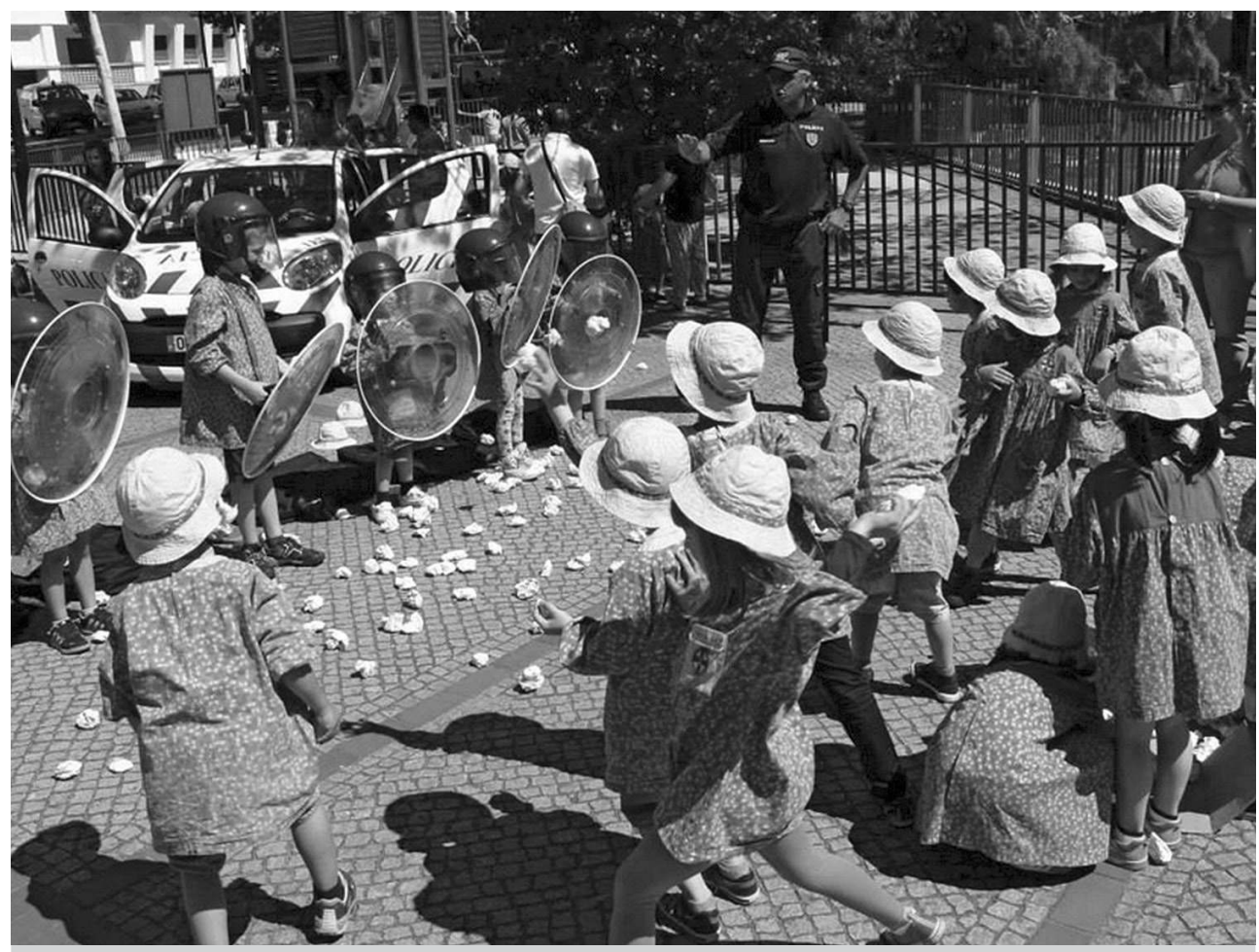

Figura 1 - Imagem de um evento organizado pela PSP e pela Câmara Municipal de Portalegre em 1 de junho de 2015. Fonte: < https://sol.sapo.pt/artigo/394663/criancas-simulammotim-e-carga-policial-em-portalegre $>$.

Diga-se que a PSP e, mais especificamente, o programa Escola Segura, organiza de maneira recorrente e sistemática este tipo de iniciativas. De facto, durante o trabalho de campo que realizei numa esquadra da PSP no concelho de Lisboa - acompanhando agentes do programa Escola Segura nos seus afazeres e diligências -, apercebi-me da centralidade daquilo que vários agentes insistiam em chamar "trabalho de prevenção". Este "trabalho" consistia sobretudo num conjunto de ações policiais que tinham como objetivo transmitir aos públicos escolares um conjunto de valores, práticas e representações normativas no domínio da moral, da civilidade, da sexualidade, da lei e da segurança. A atividade que esteve no centro da polémica de Portalegre constitui um exemplo deste tipo de ações, cuja forma mais usual é a de "ações de sensibilização" (que consistem em palestras junto de públicos escolares com o intuito de transmitir guiões de boas práticas em vários domínios da vida social) ou de "demonstrações policiais" (nas quais os públicos escolares são convidados a entrar nos espaços do policiamento, a experimentar os seus materiais e a compartilhar uma narrativa institucional sobre o crime e a segurança). Os agentes que se constituíram meus interlocutores atribuíam legitimidade a estas 
atividades, na medida em que elas ajudariam a resolver os problemas que julgavam estar na base de fenómenos como a delinquência juvenil ou a violência em meio escolar: o declínio da família e de outras sociabilidades tradicionais. ${ }^{3}$

Este artigo divide-se em duas partes distintas. A primeira - "O programa Escola Segura enquanto reforma policial" - tem como objetivo fazer um retrato genérico do programa Escola Segura enquanto programa policial que surgiu no contexto de reformas administrativas informadas pelas noções de comunidade, de proximidade policial e de prevenção da criminalidade. A segunda parte - "Prevenção, proximidade e comunidade na 'Divisão Vermelha'" - inclui duas secções e tem como objetivo geral descrever a forma como essas noções são operacionalizadas e desenvolvidas no contexto da "Divisão Vermelha". ${ }^{4}$ Na primeira secção - "Quotidiano de proximidade" - será feita uma descrição geral da forma como é operacionalizado o mandato dos agentes do programa Escola Segura, prestando especial atenção à forma como é realizada a patrulha e são formadas relações interpessoais e interinstitucionais. Na segunda secção - "O trabalho de prevenção em comunidades em crise" - será argumentado que o imaginário em torno da ideia de comunidade é fundamental para a forma como os agentes do programa Escola Segura atribuem sentido e legitimidade ao tipo de policiamento que protagonizam. Será igualmente defendido que a ideia da prevenção da criminalidade - que é nuclear no projeto do policiamento de proximidade - ganha um significado restrito e operacional através de atividades como ações de sensibilização e demonstrações policiais que, por sua vez, são vistas como agindo sobre os problemas de diferentes comunidades. Finalmente, na conclusão, serão discutidas as possíveis implicações da mobilização deste imaginário para o desenvolvimento e aplicação de um programa de policiamento de proximidade em contexto escolar.

\section{O PROGRAMA ESCOLA SEGURA ENQUANTO REFORMA POLICIAL}

O programa Escola Segura surge na década de 90 em Portugal, no contexto da implementação do policiamento de proximidade: um paradigma alternativo de policiamento que, em contraste com a abordagem reativa e circunstancial de modelos tradicionais, se baseia na construção de relações estáveis de reciprocidade com os públicos de policiamento, na descentralização das organizações policiais e num enfoque na lógica de prevenção da criminalidade (Durão

3 As reflexões deste artigo têm origem numa investigação realizada no contexto de uma dissertação de mestrado sobre o programa Escola Segura (Bento 2015). Agradeço à Doutora Catarina Frois os valiosos comentários que ajudaram a que as contribuições dessa dissertação fossem repensadas e aprofundadas neste artigo.

4 "Divisão Vermelha" constitui o nome fictício dado à esquadra que serviu de referência ao registo etnográfico e ao seu respetivo perímetro territorial. Os nomes de outros locais ou de interlocutores que possam vir a ser mencionados também permanecerão anónimos. 
2008a; Oliveira 2003, 2006; Tilley 2008). Este paradigma de policiamento tem origem em contextos anglo-saxónicos ainda durante os anos 70, onde ficou conhecido como "policiamento comunitário". A expressão policiamento de proximidade poderá, assim, ser entendida como a tradução adotada por vários países da Europa continental quando, durante os anos 90, começaram a desenvolver reformas que promoviam a descentralização e abertura das suas organizações policiais.

De facto, as designações "policiamento de proximidade" e "policiamento comunitário" tendem a ser utilizadas de modo intercambiável, apenas distinguindo áreas geográficas de aplicação de uma mesma filosofia. Podemos, no entanto, seguir a pista de Susana Durão (2014) e encarar proximidade e comunidade como termos com implicações diferentes. Assim, apesar de não haver uma definição consensual de nenhum destes termos, podemos afirmar, juntamente com essa autora, que comunidade e proximidade se diferenciam no sentido em que pressupõem diferentes disposições organizacionais e grau de abertura relativamente aos públicos de policiamento, dado que à descentralização e à pluralidade do policiamento comunitário poderá opor-se a centralização e o fechamento do policiamento de proximidade. ${ }^{5}$ Podemos ainda acrescentar que o policiamento comunitário parece pressupor a existência de comunidades enquanto objetos de segurança e, simultaneamente, enquanto parceiros ativos na sua construção (Byrne e Pease 2008; Tilley 2008; Crawford e Evans 2012). De facto, a reforma da ação policial em contextos anglo-saxónicos - nomeadamente na Grã-Bretanha - faz-se em estrita associação com uma ideologia que, por um lado, promove a transferência de responsabilidades das polícias para as comunidades e, por outro, encontra na degeneração dos laços sociais e na diminuição dos controlos informais as causas do desvio e da insegurança. ${ }^{6}$ Assim, apesar de a ideia de comunidade permanecer elusiva do ponto de vista teórico e organizacional, os seus problemas não deixam de ser vistos como estando na origem do desvio e da criminalidade e as suas virtudes como sendo as possíveis soluções.

Por sua vez, o desenvolvimento de uma polícia próxima ou de proximidade não parece pressupor este tipo de referencial holístico. Esta diferença encontra-se espelhada na forma fragmentada como o policiamento de proximidade foi implementado no contexto nacional. Em Portugal foram criados um conjunto de programas especializados que coexistem com um panorama mais geral de

5 Apesar de esta distinção servir de baliza para a discussão subsequente, ela não pretende sugerir que existem linhas de separação assim tão claras. Por exemplo, no que diz respeito ao desenvolvimento de políticas de "segurança na comunidade" (community safety) na Grã-Bretanha, existem queixas relativamente a uma excessiva interferência do Estado (Byrne e Pease 2008; Crawford e Evans 2012).

6 A teoria das “janelas partidas" desenvolvida por Kelling e Coles (1996) é amplamente citada como influência decisiva da perspetiva que atribui grande impacto à diminuição de mecanismos de controlo informal sobre o nível de criminalidade. 
prevalência do modelo reativo de policiamento. Estes programas têm o objetivo de combater a insegurança sentida por grupos sociais considerados mais vulneráveis, tais como crianças, jovens, idosos, vítimas de violência doméstica ou pequenos comerciantes. Assim, da mesma forma que existe o programa Escola Segura, também existe o Comércio Seguro ou o Apoio 65 - Idosos em Segurança.

O programa Escola Segura surge em 1992 enquanto protocolo celebrado entre o Ministério da Educação e o Ministério da Administração Interna. ${ }^{7}$ O seu objetivo inicial era promover a presença policial em torno de 17 escolas consideradas mais problemáticas (Leandro 2013). Quatro anos depois, em 1996, o programa assume a sua nomenclatura e forma atual, ganhando uma abrangência nacional, ${ }^{8}$ sendo dotado de veículos automobilizados (automóveis, ciclomotores e motociclos) e passando a contar com equipas especializadas. ${ }^{9}$ Desde então tem sido o programa de proximidade que tem beneficiado de uma maior cobertura mediática e de um maior investimento dentro da Polícia de Segurança Pública. Na verdade, desde que foi iniciado em 1992 - como resposta à dramatização dos problemas da delinquência juvenil e da violência escolar ocorrida nessa década ${ }^{10}$ (Carvalho 2006; Sebastião, Alves e Campos 2010) - o programa tem ganho crescente protagonismo, constituindo atualmente uma das principais soluções governamentais para o problema da insegurança em meio escolar (Frois e Bento no prelo).

O facto de o programa ter sido desenvolvido sob uma tutela partilhada, que inclui o Ministério da Administração Interna e o Ministério da Educação, ajuda a explicar a diversidade de atividades e objetivos que lhe foram conferidos, tais como: garantir a segurança dos estabelecimentos escolares, prevenir a delinquência juvenil, sensibilizar os alunos para os perigos da toxicodependência e do alcoolismo ou estabelecer relações de longo prazo com diferentes parceiros, como direções escolares ou representantes do poder local. ${ }^{11}$ Juntamente com este fator, deve também ser considerada a forma como o público do

7 O programa Escola Segura não é exclusivo da Polícia de Segurança Pública, sendo também desenvolvido pela Guarda Nacional Republicana. No entanto, iremos focar-nos nas estatísticas referentes à PSP, dado que este estudo foi desenvolvido com base numa aplicação do programa realizada por essa instituição.

8 Atualmente o programa tem sob a sua jurisdição 4456 estabelecimentos de ensino (inclui o superior e o particular), o que na totalidade implica o policiamento de cerca de 934.708 mil alunos. Estes dados foram retirados do Relatório Anual de Segurança Interna relativo a 2014 (MAI 2015), que abrange a ação da Guarda Nacional Republicana e da Polícia de Segurança Pública.

9 PSP, Diretiva Estratégica n. ${ }^{\circ}$ 10/2006 de 15 de maio.

10 Sebastião, Gaio e Alves (2010), a partir da análise da informação recolhida pelo Observatório da Segurança Escolar entre 2007 e 2009, concluem que existe uma dramatização desproporcional deste fenómeno na esfera mediática, o que contribui para a difusão de um alarmismo social.

11 Ver "Plano de atividades para 2014", Lisboa, Gabinete de Estudos e Planeamento - Direção Nacional da Polícia de Segurança Pública, 2013. 
policiamento realizado pelo programa Escola Segura tende a ser percecionado. Afinal, a formulação de um programa de base policial destinado a agir em contexto escolar debate-se, também ele, com a ambiguidade e contraditoriedade dos discursos e representações que recaem sobre crianças e jovens. Se, por um lado, estes tendem a ser encarados como elementos vulneráveis que devem ser protegidos, por outro, não deixam de ser percecionados como potenciais delinquentes que devem ser controlados (Pais 1996; Carvalho 2006; Sebastião, Alves e Campos 2010). Nesse sentido, esta diversidade de objetivos e atividades também poderá ser vista como uma tentativa de formalização da ambiguidade inerente à generalidade do trabalho policial (Cumming, Cumming e Edell 1996 [1965]) - dividido entre solicitações de cuidado e de controlo - que, no contexto deste programa, é particularmente realçada pelas características do seu público (Frois e Bento no prelo). De resto, não será por acaso que muitos dos agentes que se tornaram meus interlocutores sentiam a necessidade de desenvolver um conjunto de características que diziam faltar ao restante corpo policial, nomeadamente uma maior capacidade para o "dialógo", "tolerância" ou "sensibilidade" (Bento 2015).

Por sua vez, terá sido a formulação do programa Escola Segura à luz do paradigma do policiamento de proximidade que dotou esse programa de uma finalidade mais abrangente e que traz coerência a estas diferentes atividades: a prevenção da criminalidade. Na literatura especializada, a ideia de "prevenção da criminalidade" surge associada a uma grande diversidade de práticas que são desenvolvidas de maneira desigual em diferentes contextos sociais (Byrne e Pease 2008; Crawford e Evans 2012). Porém, oferecendo uma definição abrangente, poderíamos dizer que "a prevenção inclui todas as intervenções de tipo físico ou social que, através da alteração ou antecipação de certos comportamentos ou acontecimentos, têm a intenção de, pelo menos em parte, reduzir a possibilidade de acontecer um ato criminoso ou as suas consequências" (Crawford e Evans 2012: 769).

Neste sentido, práticas tão diferentes como a associação de penalização judicial a certas ações ou delitos (Drake 2012), a instalação de câmaras de vigilância (CCTV) numa zona considerada "problemática" 12 (Frois 2011), ou a realização de uma campanha publicitária sobre os perigos de comportamento irresponsável (Bowers e Johnson 2005), podem ser encaradas como diferentes aplicações de uma mesma lógica de antecipação da criminalidade.

Esta mesma ideia de prevenção de criminalidade é indispensável à definição dos objetivos e atuação do policiamento de proximidade. Para a PSP, proximidade e prevenção chegam a ser termos de significado equivalente, utilizados indistintamente para fazer referência ao mesmo tipo de ação policial. 
Por exemplo, nos Relatórios Anuais de Segurança Interna (MAI 2014, 2015), os chamados "programas de policiamento de proximidade" tendem a ser agrupados sob a rubrica "programas gerais de prevenção e policiamento", aos quais é atribuída a finalidade de "proteção de grupos sociais mais vulneráveis com o objetivo de prevenir certos fenómenos criminais" (MAI 2014: 146). Os próprios agentes com quem privei durante o trabalho etnográfico referiam-se ao grosso do seu trabalho como sendo "trabalho de prevenção", que estes associavam a todas as ações que não envolviam o uso de força física ou o recurso à penalização institucional.

Nas próximas secções serão apresentadas e discutidas as formas através das quais os agentes do programa Escola Segura da "Divisão Vermelha" operacionalizam as noções de prevenção, proximidade e comunidade. Veremos que interagir com alunos durante as patrulhas, conviver com professores e funcionários ou marcar presença em "reuniões de parceiros" constitui para estes agentes trabalho de proximidade e/ou de prevenção. No entanto, também veremos que a ideia de prevenção assume um significado mais estrito através de atividades que se destinam a promover determinados valores e representações junto daquilo que os agentes entendem ser comunidades em crise.

\section{PREVENÇÃO, PROXIMIDADE E COMUNIDADE NA “DIVISÃO VERMELHA”}

\section{Quotidiano de proximidade}

O programa Escola Segura da "Divisão Vermelha", situado no centro do concelho de Lisboa, dispõe de uma equipa constituída por 15 agentes (sete do sexo masculino, oito do sexo feminino), liderada por um chefe, e dotada de três viaturas automóveis e dois motociclos para patrulhar uma área que abrange cerca de 50 estabelecimentos de ensino com quase 60 mil alunos. ${ }^{13}$ Como veremos,

13 A Polícia de Segurança Pública (PSP) organiza-se no território nacional de maneira hierárquica e funcionalmente diferenciada. A sua estrutura é encabeçada pela Direção Nacional, à qual estão subordinados diferentes Comandos Territoriais. Estes comandos abrangem divisões e esquadras que, por sua vez, correspondem a diferentes áreas de influência territorial. Aquilo que caracteriza uma divisão é o facto de, para além de ter uma unidade operacional, ou seja, uma esquadra, conter também uma unidade administrativa. Isso faz com que haja menos divisões que esquadras, mas, ao mesmo tempo, que a estas corresponda uma maior área territorial. No Comando Metropolitano de Lisboa (CML), o programa Escola Segura é desenvolvido através da afetação de elementos policiais a cada esquadra. A um número específico de agentes corresponde, assim, um número concreto de estabelecimentos escolares que são abrangidos por esse território de influência. Este modo de distribuição dos agentes e organização do trabalho policial corresponde àquilo a que podemos chamar uma aplicação descentralizada do programa, feita com base na unidade operacional da esquadra. No caso da "Divisão Vermelha", a unidade de organização corresponde à divisão e não à esquadra, o que implica, por um lado, a concentração dos recursos humanos e materiais que estariam espalhados por diferentes esquadras e, por outro, o patrulhamento da totalidade das escolas que pertenceriam a essas zonas de influência. Assim, podemos dizer que a "Divisão Vermelha" desenvolve uma versão centralizada [continua] 
as rotinas destes agentes refletem e excedem a amplitude do mandato que lhes foi conferido; ou seja, a patrulha de visibilidade, as palestras e as reuniões de parceiros são atividades que constituem apenas a base do quotidiano do programa.

Durante a semana, todos os dias de manhã, saem da "Divisão Vermelha" três carros de polícia. A bordo vão seis agentes que se distribuem por três zonas diferentes. Em situações ideais, a cada equipa corresponde uma zona, numa ligação que se pretende estável e duradoura. A ideia é contribuir para uma relação de longo prazo entre determinados agentes e as escolas que estes patrulham. No entanto, várias contingências obrigam a constantes reformulações, muitas vezes relacionadas com a indisponibilidade ou ausência de elementos. Este patrulhamento tem uma estrutura dinâmica e flexível, determinada em virtude de avaliações feitas em contexto de esquadra, que têm o propósito de definir quais as escolas que irão ser abrangidas pelas ações dos agentes num determinado dia. Normalmente, as escolas patrulhadas são as que, por uma razão ou outra, ganharam a reputação de serem "problemáticas". No entanto, uma briga recente ou um aviso de um professor pode mudar essa ordem, reestruturando, assim, a ação dos agentes.

Isso significa que o levantamento de problemas no terreno, através de diferentes interações, influi diretamente no exercício do policiamento. Como refere Durão (2008b), o tipo de ação protagonizada pelo grosso dos agentes que integram as forças policiais é qualitativamente diferente daquela realizada pelos agentes dos programas de proximidade. ${ }^{14}$ Enquanto os primeiros agem com distanciamento face ao seu público, os segundos dependem da produção de um saber em rede e do desenvolvimento de uma abordagem inter-relacional. Por essa razão, o patrulhamento das escolas obedece a um ritmo próprio, com uma cadência definida a pensar na recolha de informações; a paragem numa escola implica mais que um patrulhamento desinteressado, implica também uma estadia demorada que propicie a conversa com alunos, professores e funcionários. Neste contexto, a construção da "proximidade" com certos elementos revela-se fundamental. Como afirmou um agente:

"O porteiro [da escola] é muito importante porque é aquele que tem contacto direto com todos os alunos e nos consegue alertar para os grupinhos bons e os grupinhos maus, se nos intervalos passam pessoas estranhas

do programa. Na perspetiva dos seus agentes, este modelo centralizado traz benefícios a vários níveis, em particular na gestão de recursos e ocorrências e na criação de um ambiente de trabalho propício à confraternização e à troca de informações. Segundo o que me foi transmitido por alguns agentes, a decisão de desenvolver esta versão centralizada do programa foi tomada ao nível da divisão, que teve em conta o número desproporcional de escolas face ao número de esquadras em certas zonas.

14 Durão (2008b) também estabelece diferenças entre o patrulhamento realizado por agentes apeados e o patrulhamento realizado por agentes que viajam a bordo do carro de patrulha. 
junto às escolas, se há contacto com outros indivíduos que não pertencem à comunidade escolar... [Também são importantes o] auxiliar que anda junto dos alunos e a direção, pois sem o apoio deles não é possível resolver algumas questões".

No entanto, este ritmo pode sempre ser interrompido por uma chamada de emergência. O programa da "Divisão Vermelha" tem uma ligação direta com as escolas através de um telemóvel que é fornecido a cada agente. Este facto concede ao programa uma faceta de policiamento reativo que seria pouco previsível num quadro de proximidade.

Outra parte do tempo destes agentes é ocupada com aquilo que designarei como ações diplomáticas. Desde o início que um dos objetivos atribuídos ao programa Escola Segura é o de estabelecer relações com diferentes parceiros da comunidade educativa. Assim, uma parte do dia-a-dia dos agentes é passada em reuniões com membros de direções de escola, representantes do poder local ou membros de diferentes associações. Participar em "conselhos consultivos", "reuniões de parceiros" ou "assembleias escolares" ajuda a construir relações de confiança que, no futuro, oferecem outra margem de manobra aos agentes e alargam a rede de contactos. No entanto, a manutenção destas relações interinstitucionais assume ainda outra função: ajudar a garantir recursos e apoios para o desenvolvimento de outras atividades, como demonstrações policiais ou ações de sensibilização. Grande parte do tempo dos agentes é ocupado com a realização destas atividades, que, apesar de constituírem parte integrante das funções destes polícias, exigem meios que podem não lhes ser disponibilizados. De facto, uma das queixas frequentes dos agentes tem que ver com a excessiva burocracia e a indisponibilidade da Direção Nacional para ceder recursos, o que obriga a um esforço contínuo de negociação junto de outros parceiros, como juntas de freguesia, associações de pais, instituições privadas de solidariedade social ou direções de escola. Estas diligências exigem o exercício daquilo que se assemelha a um bom senso diplomático que garante a construção de relações de reciprocidade.

Convém, no entanto, contrariar a ideia de um mandato fixo e rígido, cujo conteúdo é ditado apenas pela lei ou pela organização policial. Apesar de os mandatos associados ao policiamento escolar terem, na maior parte dos casos, a particularidade de serem abrangentes do ponto de vista formal (Casella 200 l ; Brown 2006; Kupchik e Bracy 2010), estes não deixam de se estender para além das exigências oficiais, estando permanentemente sujeitos à imprevisibilidade do quotidiano ou ao surgimento de novas prioridades institucionais e políticas. De resto, tem sido recorrentemente notado que tanto os mandatos como as culturas policiais parecem resistir, na sua generalidade, a qualquer definição demasiado restrita ou essencializada (Durão 2010; Gonçalves 2007, 2011 ; Westmarland 2008). Por exemplo, desde a criação do programa, os agentes da 
"Divisão Vermelha" passaram a integrar o combate ao absentismo escolar ${ }^{15}$ ou as ocorrências ligadas a disputas sobre o poder paternal (quando ocorridas em perímetro escolar) como parte das suas funções habituais. Da mesma forma, o facto de muitos destes agentes se terem tornado, como me foi descrito, "bengalas" de algumas direções, leva a que estes possam ser solicitados a desempenhar funções cujo conteúdo é extremamente diversificado, abrangendo tanto a gestão do trânsito à frente do estabelecimento escolar como o acompanhamento de alunos mais novos em excursões.

Esta diversidade de ações e tarefas não deve ser vista, no entanto, como o produto exclusivo da colaboração de agentes do programa Escola Segura com as diferentes direções escolares. De facto, pais, professores, funcionários, mas também alunos, podem instrumentalizar a presença policial em quotidiano escolar. Um agente pode ser solicitado por algum pai que desconfie de certos movimentos junto do gradeamento escolar, por um docente que ache útil que os alunos recebam uma palestra sobre um determinado tema, mas também por um aluno que sinta que foi injustiçado pelos seus colegas. Neste sentido, é importante reconhecer que o mandato destes agentes é o produto de um conjunto de interações complexas cujo alinhamento e configuração nem sempre são previsíveis.

\section{O trabalho de prevenção em comunidades em crise}

Como vimos, em Portugal, o conceito de policiamento de proximidade foi operacionalizado com recurso à criação de um conjunto diversificado de programas policiais especializados nos problemas de grupos sociais considerados mais vulneráveis. Vários autores têm vindo a alertar para a ineficácia deste modelo de implementação, que acaba por deixar relativamente incólume a prevalência do modelo reativo de policiamento (Oliveira 2003, 2006; Durão 2008a, 2014). De facto, num argumento ao qual já fizemos referência, Susana Durão (2014: 129) defende que tanto a noção de proximidade como a de comunidade permanecem "metáforas mobilizadoras" no contexto português. A mesma autora acrescenta ainda que existem razões objetivas para que a metáfora da proximidade constitua a referência em certos países, enquanto noutros se constata a prevalência da metáfora da comunidade. Assim, terá sido sobretudo a dependência burocrática e administrativa na implementação e execução de noções alternativas de policiamento que terá levado a que Portugal reivindicasse a proximidade como metáfora essencial, enquanto noutros países terá sido a descentralização efetiva das organizações policiais e a consequente participação ativa dos públicos de policiamento na construção da segurança que terá tornado o termo policiamento comunitário mais apropriado.

15 Estas diligências consistem em deslocações aos domicílios onde vivem alunos que foram sinalizados pelas escolas. 
O registo etnográfico do quotidiano do programa Escola Segura revelou, no entanto, a presença da metáfora da comunidade de uma outra forma. Muitos dos agentes com quem privei encontravam no declínio dos valores tradicionais, na crise da instituição familiar e na decadência dos contextos de sociabilidade a origem da delinquência e do desvio juvenil. De facto, a ideia de que os jovens que estes agentes policiavam eram provenientes de comunidades desestruturadas - descritas como lugares desolados onde já não se pode confiar nas famílias para transmitir valores morais e de disciplina - era veiculada de forma recorrente. Era enfatizada a forma como a ausência de figuras centrais que se ocupassem da educação de crianças e jovens levava a que estes ficassem "à mercê" dos tempos mortos na rua, onde, por sua vez, referências menos desejáveis poderiam exercer a sua influência. Assim, a fragilidade dos vínculos sociais era constituída como a causa de fenómenos tão dispersos como a violência escolar ou a toxicodependência entre os jovens. Ao aderir a esta narrativa, os agentes acabavam por invocar de forma implícita o imaginário em torno da ideia de comunidade - e, mais especificamente, de comunidade em crise - para conferir sentido e legitimidade ao tipo de policiamento que realizavam. Tal visão encontra-se espelhada nas declarações de vários agentes. Por exemplo:

"Com facilidade, os pais acabam por se demitir um pouco desta função de educar, de transmitir valores. [...] Para mim, a essência está na família, digam o que disserem. Ora, se [os valores] não são transmitidos, a escola tem aí a função de complementaridade e de se substituir um pouco a essa família. Quando isso não acontece, é muito difícil pôr estes miúdos na linha".

Ou ainda:

“... nós entramos num bairro e continua-se a ver caixotes do lixo virados, as ruas não estão lavadas como haviam de estar... Nós não podemos dar só casas a estas pessoas. Devemos de algum modo ensiná-las a preservar o ambiente que as rodeia. Nós entramos nalguns prédios e o elevador está completamente destruído, tudo queimado..."

Outro agente também referiu:

"Nota-se, visivelmente, quando vamos a uma escola de bairro: os miúdos, a cultura, a educação. Nota-se que há uma quebra de valores. Os pais que trabalham, trabalham muitas horas e não dão atenção aos filhos. Muitos deles nem sabem o que se passa com eles".

Esta visão em torno da degradação dos valores, costumes e relações sociais aplicava-se sobretudo àquilo a que os agentes chamavam os "bairros". De facto, 
se a área geográfica coberta por estes agentes do programa Escola Segura é extensa, estes não deixam de fazer a sua própria racionalização do espaço, elaborando as suas próprias categorias e demarcações. À semelhança do que já descreveu Susana Durão (2008b: 93), mesmo os agentes de proximidade tendem a partilhar com a generalidade da força policial um mapa sociomoral da cidade, no qual diferentes zonas correspondem a diferentes tipos de população que, por sua vez, são vistos como requerendo diferentes tipos de abordagem policial. $^{16}$

Assim, para além de moralmente comprometidos, os "bairros" eram também considerados territórios de "intervenção difícil". Era nos "bairros" que os agentes esperavam que a imagem da instituição estivesse mais degradada e, por isso, a sua presença fosse rejeitada de maneira mais agressiva. Isto revela como estes agentes do programa Escola Segura, à semelhança dos seus colegas no "carro de patrulha", sentem a conotação negativa da sua atividade; e como os "bairros" acabam por ser percecionados como um foco dessa desconfiança face à profissão e instituição que representam. De facto, estas populações estavam associadas a uma solidariedade negativa, responsável por mobilizações agressivas e impulsivas em torno das escolas, sendo frequentemente relatada a maneira como o "bairro todo" se junta no recinto sempre que se testemunham episódios problemáticos. Aos agentes que tomam parte em ações nestes lugares é frequentemente aconselhada uma postura negocial, mas assertiva: “... no bairro, se calhar, estas pessoas sentem-se mais fortes, um pouco protegidas pelo ambiente [...]. Temos de usar um pouco mais de bom senso para gerir as situações [...]. Se não houver sangue-frio, é mais difícil”.

Este tipo de racionalização em torno da delinquência e das zonas onde esta é produzida acaba por atribuir ao "trabalho de prevenção" um conteúdo e uma finalidade particulares. O registo etnográfico revelou que o conceito de prevenção assume um significado mais estrito através das atividades que têm em comum a função de transmitir valores e normas no âmbito de um conjunto diversificado de domínios da vida social, como a moral, a civilidade, a sexualidade, a lei ou a segurança. Tal não será por acaso: quando existe uma perceção partilhada de que a família, a escola ou as diferentes comunidades são incapazes de transmitir os valores considerados indispensáveis à formação de crianças e jovens, atividades como as ações de sensibilização ganham outra importância.

É também através destas atividades que a "prevenção" assume um conteúdo prático e operacionalizável para a PSP. Segundo o Relatório Anual de Segurança Interna relativo a 2013 (MAI 2014: 148), estas atividades constituem “ações

16 Durão (2008b) descreveu este mapa como dividindo a cidade numa "parte de cima", habitada por indivíduos de classe média a serem protegidos, e uma "parte de baixo", habitada por indivíduos afetados pela pobreza e precariedade a serem controlados. 
dirigidas à comunidade escolar" que incluem: "sessões de sensibilização e informação, demonstrações, exercícios de prevenção, e visitas a instalações das Forças de Segurança”. Estas atividades estão inclusivamente sujeitas a um quadro de objetivos - desenhado e imposto pela Direção Nacional - que promove a sua realização intensiva através da criação de metas quantitativas com caráter vinculativo. A título de exemplo, em 2014, foram realizadas a nível nacional 19.409 ações dirigidas a 1.818 .535 alunos. ${ }^{17}$ Será a descrição destas atividades que faremos de seguida, apresentando a título de exemplo os casos das ações de sensibilização e das visitas guiadas à esquadra, que são, ao mesmo tempo, as ações realizadas de maneira mais regular no contexto da "Divisão Vermelha".

As "ações de sensibilização" consistem em palestras que incidem sobre tudo o que é pensado como causa ou consequência de comportamento desviante ou delinquente: bullying, toxicodependência, roubo, alcoolismo, segurança rodoviária, etc. Num tom assertivo, os agentes dirigem-se a plateias de alunos tentando ilustrar as consequências profundamente negativas que comportamentos delinquentes podem ter para as suas vidas futuras. Para o realçar, fazem uso de quadros legais que abrangem jovens e crianças, entrando em detalhes sobre a Lei Tutelar Educativa ${ }^{18}$ ou a legislação de combate à droga. ${ }^{19}$ A este respeito, os 16 anos definidos como o limite da abrangência da Lei Tutelar Educativa constituem um recurso simbólico precioso, promovendo a dissuasão por meio do receio de represálias legais. ${ }^{20}$ Pelo facto de os agentes assumirem, neste contexto, as funções de um professor ou de um mentor, isto é, alguém com uma certa autoridade e experiência de vida, não é raro socorrerem-se de histórias pessoais para fazer passar a sua mensagem. De maneira semelhante, é igualmente comum imprimirem alguma subjetividade ao próprio conteúdo das apresentações. Por exemplo, no decorrer de uma apresentação sobre os perigos do cyberbulling, um agente fez questão de tornar clara a ideia de que raparigas muito novas se expunham "demais" no Facebook, alertando assim para os vários perigos que estas corriam.

Estas sessões, que abrangem alunos de todos os ciclos de ensino (exclusive o superior), têm a duração de 30/40 minutos e são feitas com acompanhamento dos docentes. Por vezes, os temas das palestras são definidos a pedido

17 Informação retirada do Relatório Anual de Segurança Interna de 2014. Estes dados estatísticos figuram invariavelmente no Relatório Anual de Segurança Interna de todos os anos, sendo promovidos como um dos principais indicadores do sucesso do programa. No terreno, porém, os agentes queixam-se da excessiva pressão em torno da realização destas atividades, defendendo que pode ser prejudicial para o patrulhamento ou para a disponibilidade de resposta a chamadas de emergência.

18 Lei n. ${ }^{\circ} 166 / 99$, de 14 de setembro.

19 Decreto-Lei n. ${ }^{0} 15 / 93$, de 22 de janeiro.

20 A Lei Tutelar Educativa estipula que a medida mais grave a que podem ser sujeitos os menores, entre as idades de 12 e 16 anos, que cometam atos qualificados como crime seja o internamento em centro educativo. 
de pessoal escolar, que sente que existem lacunas específicas em determinados aspetos da formação ética e moral dos alunos. No entanto, estas palestras não assumem apenas um papel moralizador e dissuasivo, mas também reflexivo. A esse respeito são particularmente interessantes os momentos em que estes agentes se veem obrigados a prestar esclarecimentos sobre a própria lei, que também figura como um conteúdo independente das suas palestras. Estas explicações obrigam a uma racionalização da ação policial através de demonstrações da pertinência dos quadros legais que lhe servem de orientação. Isto implica tornar o texto da lei legível, coerente e objetivo para os alunos que assim o exijam. Por outras palavras, a estes agentes não basta fazer cumprir a lei, cabendo-lhes também tornar claras as razões pelas quais esta deve ser cumprida.

No entanto, o "trabalho de prevenção" não procura apenas ajudar a colmatar a "ausência" de comunidade, mas também recuperar o lugar que a polícia e os polícias pensam ter perdido nela. A polémica que deu o mote a este artigo revela de forma clara a desconfiança que existe relativamente à polícia e ao policiamento. Por outro lado, de forma algo irónica, a mesma ação policial que foi considerada controversa é representativa de uma dimensão do policiamento de proximidade - institucionalmente promovida e amplamente desenvolvida - que espera agir sobre as representações e práticas das comunidades,

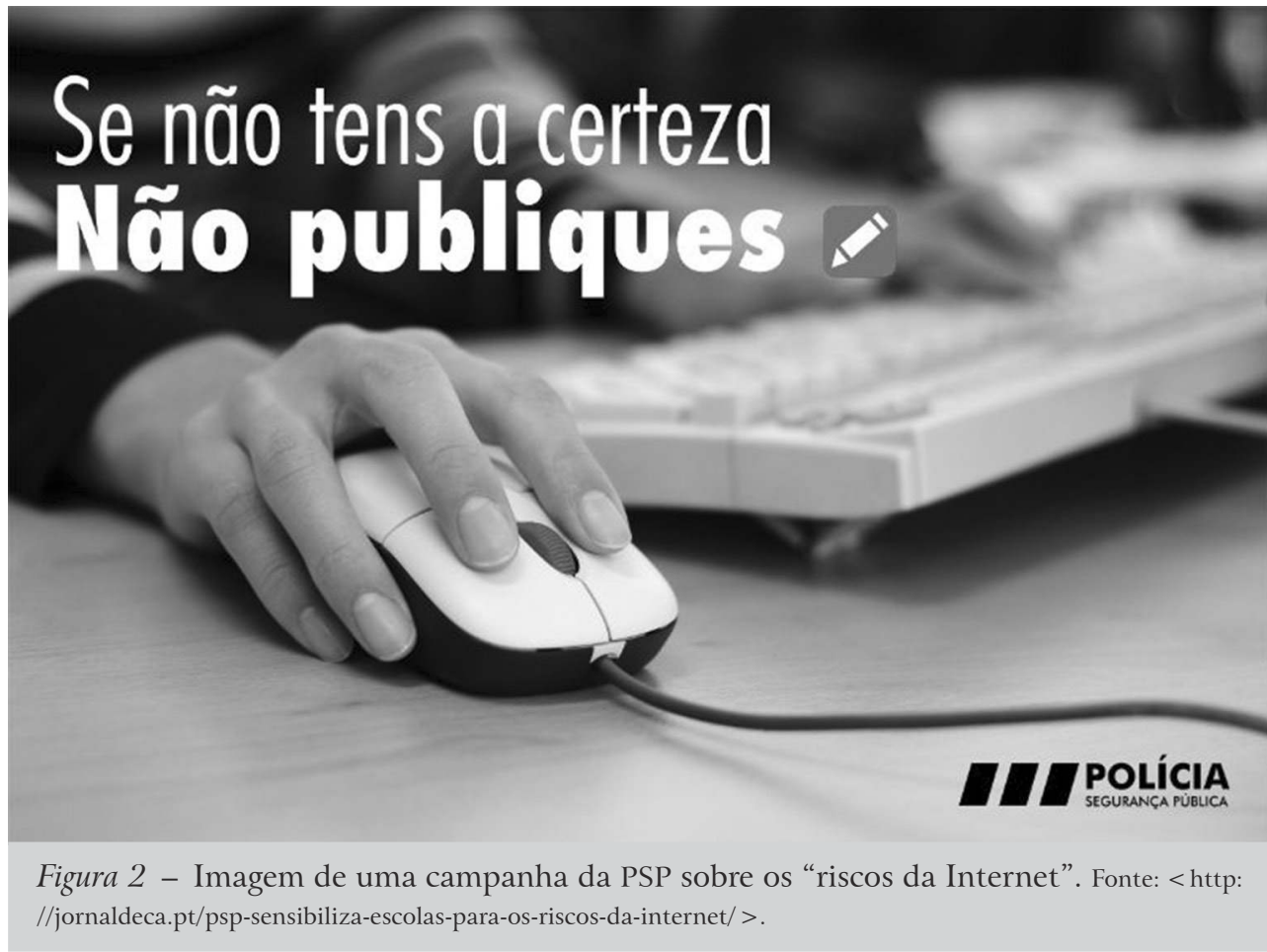




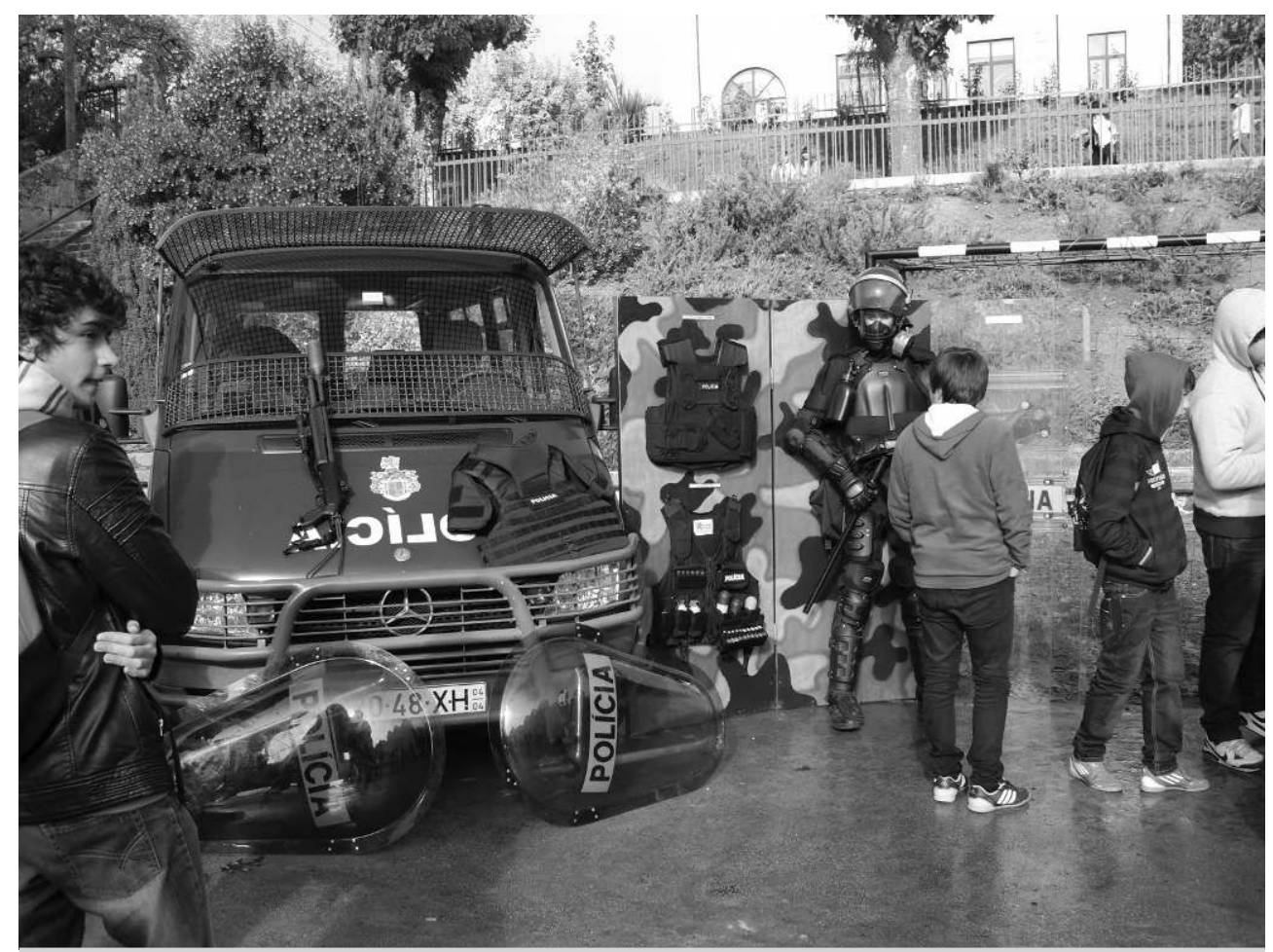

Figura 3 - Exemplo de uma demonstração com material policial. Fonte: < http://policiamentodeproximidade.blogspot.pt/2012/11/policia-de-seguranca-de-lamego-e equipa.html >.

não só com o objetivo de combater a perversão da moralidade e dos costumes, mas também de promover uma nova adesão à instituição policial. É com esse intuito que professores e alunos são convidados a entrar nos espaços do policiamento, a experimentar os seus materiais e a participar em encenações em torno da instituição policial, do seu quotidiano e da sua função social.

Vejamos o caso das visitas guiadas à "Divisão Vermelha". Estas focam-se essencialmente na transmissão de valores e representações ligadas à segurança e ao combate à criminalidade. Durante aproximadamente uma hora, agentes do programa Escola Segura guiam alunos (numa faixa etária entre os 8 e os 12 anos) pelas instalações da esquadra, explicando as funções desempenhadas por cada sala e unidade operacional. As turmas seguem em fila, acompanhadas pelos respetivos professores, ouvindo atentamente as exposições. Com detalhe, é transmitido o propósito da secção de atendimento, da sala de apoio à vítima e até das salas de identificação ou das celas de detenção temporária. A explicação que acompanha a visita destas salas é feita muitas vezes com recurso a distinções de base normativa e moral. Assim, por exemplo, à entrada das celas de detenção é dito que "estas servem para prender os meninos que se portaram 
muito mal enquanto não vão para tribunal”. De forma semelhante, ao chegar às salas de identificação, é feito um "jogo" através do qual se dividem as turmas em dois grupos e se coloca cada grupo em lados opostos do vidro unidirecional. Os agentes explicam que de um lado estão os "maus", que assumem números diferentes para serem identificados pelas "vítimas", estando estas do outro lado, invisíveis.

À passagem pela secção administrativa, são utilizados elementos decorativos (quadros, material histórico, etc.) para dar conta da história da PSP, dos seus símbolos e das suas referências. Faz-se notar a evolução dos equipamentos, dos uniformes e dos próprios quadros de recrutamento. Por último, é feita uma demonstração interativa de equipamento policial, na qual alunos entram e saem de diferentes carros de polícia (por exemplo, carrinhas de intervenção, automóveis da divisão de trânsito ou do programa Escola Segura), fazem tocar a sirene, envergam capacetes e joelheiras e empunham bastões. Supervisionados, os alunos "brincam" durante algum tempo com este material, sendo ocasionalmente interrompidos por breves explicações dos agentes. As visitas acabam com uma fotografia que junta alunos, professores e polícias. Outras atividades, como eventos recreativos organizados em conjunto com as escolas ou o poder local, tentam transmitir os mesmos valores. Por exemplo, durante a minha estadia na "Divisão Vermelha", estava a ser organizada uma festa local, na qual alunos participariam envergando uniformes da Polícia de Segurança Pública e gerindo uma "mini-esquadra".

\section{CONCLUSÃO}

"A palavra evoca tudo o que nos falta para nos sentimos seguros e confiantes. Comunidade tornou-se outro nome para paraíso perdido" (Bauman 2001: 3).

“... Gemeinschaft, uma comunidade fechada, repleta de relações afetivas íntimas, que é delimitada por uma cultura idiossincrática que sustém essas relações e as dota de meios de expressão simbolicamente ricos. Ela encontra a sua consagração nos espaços comuns das aldeias, não no mercado livre de bens ou ideias" (Gellner 1995: 13).

$\mathrm{O}$ argumento geral que foi desenvolvido neste artigo defende que a implementação e definição do programa Escola Segura da PSP depende da realização sistemática de atividades que têm como função a transmissão de normas e valores. É através destas iniciativas que a ideia de prevenção da criminalidade - central ao projeto do policiamento de proximidade - ganha um peso organizacional específico e uma definição operacional comum. Por sua vez, o registo etnográfico tendeu a revelar que, ao dar palestras sobre os perigos de 
estupefacientes ou ao guiar alunos pelos meandros de uma esquadra, a maioria dos agentes do programa Escola Segura está na verdade a endereçar aquilo que considera serem problemas subjacentes a diferentes comunidades. Por outras palavras, os problemas que afetam a escola acabam por ser equacionados como sendo os problemas dos "bairros", das suas famílias e dos valores que informam e estruturam essas relações sociais. Por essa razão, ao analisar a atuação do programa Escola Segura, acabam por ser tão relevantes as especificidades de crianças e jovens enquanto públicos de policiamento, como as comunidades que os meus interlocutores imaginam como partilhando - ou como devendo partilhar - um certo modo de vida e características. Afinal, são essas comunidades que estes agentes veem como carecendo de intervenção.

As implicações associadas à mobilização deste ideal não devem deixar de ser problematizadas. A comunidade constitui um ideal político simultaneamente nostálgico e utópico. Se, por um lado, ela é pensada enquanto mundo social "extinto", no qual imperava a reciprocidade, a homogeneidade e os fortes vínculos sociais, por outro, é também pensada enquanto mundo que é possível recriar. Zygmunt Bauman refere como a própria palavra se tornou um sinónimo de segurança, conforto e previsibilidade e invoca uma espécie de "paraíso perdido": “... a comunidade representa o tipo de mundo que, infelizmente, já não está disponível para nós, mas que não deixamos de desejar voltar a possuir e habitar" (Bauman 2001: 3). Não deve ser ignorado o modo como estas ansiedades e desejos são sugestivos de uma utopia conservadora. Como refere Gellner (1995: 13), não é por acaso que durante o século XX a Gemeinschaft constitui o ideal utópico contrário à Gesellshaft: uma "sociedade aberta" onde prevaleceria o cosmopolitismo, o individualismo e o mercado livre.

A comunidade, quando pensada neste sentido, pressupõe um ideário pouco compatível com as exigências de reformas que pretendem tornar as polícias mais abertas, democráticas e inclusivas. E, de facto, não é por acaso que, ao tentar formular uma definição consensual de "policiamento comunitário", muitos acabam por esbarrar nas limitações impostas por essa mesma terminologia. Quem constitui a comunidade que é mencionada? Onde é que ela começa e acaba? Quem são aqueles que lhe pertencem e a constituem, e quem são os seus excluídos e marginais? E, se essa comunidade é percecionada como estando em crise e sob ataque, de quem e de quê precisa ela de ser protegida?

O programa Escola Segura surge num contexto marcado pela crescente mediatização e politização de um difuso sentimento de insegurança, recorrentemente essencializado enquanto receio de uma criminalidade e violência originadas em minorias culturais, étnicas e migratórias (Wacquant 2009; Cunha e Durão 2011). Surge igualmente num momento de crise da instituição escolar, cada vez mais vista como sendo incapaz de cumprir promessas de ascensão social e de inclusão de um público diversificado. Tanto os receios como as respostas políticas em torno da violência escolar e juvenil devem ser 
analisados à luz destas tendências. Sebastião, Alves e Campos (2003) referem como face ao problema da insegurança escolar foram formulados dois tipos de discursos e desenvolvidos dois tipos de soluções (em certa medida contraditórias): a "abordagem pedagógica" e a "abordagem policial". Enquanto a primeira encontra a origem dos conflitos na ineficácia dos próprios mecanismos escolares, propondo para esse efeito uma série de medidas sociopedagógicas, ${ }^{21}$ a segunda parte do pressuposto de que a violência e a indisciplina que ocorrem no interior da escola emanam do seu exterior, “... de zonas de periferia degradada, marginal ou de bairros sociais” (2003: 47). Esta última abordagem preconiza, portanto, a necessidade de elementos policiais que defendam o espaço escolar da intrusão de elementos provenientes de comunidades consideradas desajustadas e desordeiras.

Didier Fassin (2013), com base numa etnografia realizada nas periferias de Paris onde acompanhou agentes das brigadas "anticrime", argumenta que a ação policial nessas zonas contribui sobretudo para a construção de uma "ordem social" e não para a manutenção de uma ordem pública. Para este autor, o facto de esses agentes agirem desproporcionalmente sobre minorias religiosas e étnicas com vista ao cumprimento de objetivos políticos leva a que estes sirvam sobretudo o propósito de produzir estigmatização e distanciamento; ou, nas palavras de Fassin, o propósito de "relembrar a cada um qual é o seu lugar" (2013: 200). Devemos questionar se os agentes do programa Escola Segura não estarão também a contribuir para a reprodução de uma ordem social na qual a escola permanece um espaço sitiado e uma instituição habitada por uma comunidade escolar restrita e seletiva. Mesmo sendo esse o caso, será de relembrar que o facto de a ação do programa Escola Segura recair sobre a conduta de crianças e jovens implica, para muitos dos agentes que acompanhei, um aprofundamento da perceção de que objetos de controlo podem constituir simultaneamente objetos de cuidado, tal como implica o reequacionamento da forma como a polícia pretende aproximar-se do seu público, prevenir a criminalidade e agir sobre as comunidades que pensa estarem em crise.

21 Os autores defendem que o discurso subjacente a este tipo de soluções parte do pressuposto de que a indisciplina e a violência verificadas em espaço escolar têm origem na frustração decorrente da incapacidade de atingir o sucesso escolar. Em causa estão soluções como a criação do programa TEIP (Territórios Escolares de Intervenção Prioritária) ou a adaptação dos currículos dos alunos com fracos resultados (Sebastião, Alves e Campos 2003). 


\section{BIBLIOGRAFIA}

BAUMAN, Zygmunt, 2001, Community: Seeking Safety in an Insecure World. Cambridge, Polity Press.

BENTO, Afonso, 2015, Um Estudo Qualitativo do Policiamento Escolar Português: O Programa Escola Segura. Lisboa, ISCTE - Instituto Universitário de Lisboa, tese de mestrado em Sociologia.

BOWERS, Kate, e Shane JOHNSON, 2005, "Using publicity for preventive purposes", em Nick Tilley (org.), Handbook of Crime Prevention and Community Safety. Portland, OR, Willan Publishing, 329-354.

BROWN, David, 2006, "Understanding and assessing school police officers: a conceptual and methodological comment", Journal of Criminal Justice, 34: 591-604.

BYRNE, Simon, e Ken PEASE, 2008, "Crime reduction and community safety", em Tim Newburn (org.), Handbook of Policing. Portland, OR, Willan Publishing, 341-372.

CARVALHO, Maria João Leote de, 2006, "Jovens, espaços, trajectórias e delinquências", Sociologia: Problemas e Práticas, 49: 71-93.

CASEllA, Ronnie, 2001, Being Down: Challenging Violence in Urban Schools. Nova Iorque, Teachers College Press.

CRAWFORD, Adams, e Karen EVANS, 2012, “Community safety and crime prevention”, em Mike Maguire, Rod Morgan e Robert Reiner (orgs.), The Oxford Handbook of Criminology. Oxford, Oxford University Press, 769-805.

CUMMING, Elaine, Ian CUMMING, e Laura EDELL, 1996 [1965], “The policeman as a philosopher, guide and friend", em Robert Reiner (org.), Policing. Aldershot, Ashgate, 139-150.

CUNHA, Manuela Ivone, e Susana DURÃO, 201 1, “Os sentidos da segurança: ambiguidades e reduções", Etnográfica, 15 (1): 53-66.

DraKe, Deborah, 2012, Prisons, Punishment and the Pursuit of Security. Londres, Palgrave Macmillan.

DURÃO, Susana, 2008a, Patrulha e Proximidade: Uma Etnografia da Polícia em Lisboa. Coimbra, Nova Almedina.

DURÃO, Susana, 2008b, "A rua dos polícias: visão itinerante", em Graça Índias Cordeiro e Frédéric Vidal (orgs.), A Rua: Espaço, Tempo e Sociabilidade. Lisboa, Livros Horizonte, 79-96.

DURÃO, Susana, 2010, “Carreiras subjectivas entre agentes da Polícia de Segurança Pública em Portugal”, Dilemas: Revista de Estudos de Conflito e Controle Social, 3 (8): 9-44, disponível em < https://revistas.ufrj.br/index.php/dilemas/article/view/7169> (última consulta em junho de 2017).

DURÃO, Susana, 2014, "Policiamento de proximidade em Portugal: limites de uma metáfora mobilizadora”, em Susana Durão e Márcio Darck (orgs.), Polícia, Segurança e Ordem Pública: Perspetivas Portuguesas e Brasileiras. Lisboa, Imprensa de Ciências Sociais, 101-134. FASSIN, Didier, 2013, Enforcing Order: An Etnography of Urban Policing. Cambridge, Polity Press.

FROIS, Catarina, 201 1, Vigilância e Poder. Lisboa, Editora Mundos Sociais.

FROIS, Catarina, e Afonso BENTO, no prelo, "Quando o Estado cuida: a amplitude do mandato das forças de segurança” em Antónia Pedroso de Lima (org.), Cuidar em Momentos de Crise: Apoio, Solidariedade e Mutualidade. Lisboa, Editora Mundos Sociais. 
GELLNER, Ernest, 1995, “The politics of anthropology”, em Ernest Gellner, Anthropology and Politics: Revolution in the Sacred Grove. Oxford, Blackwell Publishing, 11-26.

GONÇALVES, Cândido Gonçalo Rocha, 2007, A Construção de Uma Polícia Urbana, Lisboa, 1890-1940. Lisboa, ISCTE - Instituto Universitário de Lisboa, tese de mestrado em Sociologia.

GONÇALVES, Gonçalo Rocha, 2011, "Modernização policial: as múltiplas dimensões de um objecto historiográfico", CIES e-Working Paper 116, disponível em < http://www.c ies.iscte.pt/destaques/documents/WP_CIES1 16_Goncalves.pdf > (última consulta em junho de 2017).

KELliNG, George L., e Catherine M. COLES, 1996, Fixing Broken Windows. Nova Iorque, Touchstone Books.

KUPCHIK, Aaron, e Nicole L. BRACY, 2010, "To protect, serve, and mentor? Police officers in public schools", em Torin Monahan e Rodolfo Torres (orgs.), Schools under Surveillance: Cultures of Control in Public Education. Londres, Rutgers University Press, 2 1-37.

LEANDRO, Alexandra, 2013, Limites, Desordens e Mediações: Uma Etnografia do Espaço Escolar. Lisboa, ISCTE - Instituto Universitário de Lisboa, tese de doutoramento em Antropologia.

MAI - MINISTÉRIO DE ADMNISTRAÇÃO INTERNA, 2014, Relatório Anual de Segurança Interna - Ano 2013. Lisboa, Gabinete do Secretário-Geral do Sistema de Segurança Interna.

MAI - MINISTÉRIO DE ADMNISTRAÇÃO INTERNA, 2015, Relatório Anual de Segurança Interna - Ano 2014, Lisboa, Gabinete do Secretário-Geral do Sistema de Segurança Interna.

OLIVEIRA, José Ferreira, 2003, "Os modelos de policiamento e as políticas de segurança: a emergência do policiamento de proximidade", em Juan Mozzicafredo, João S. Gomes e João Baptista (orgs.), Ética e Administração: Como Modernizar os Serviços Públicos? Oeiras, Celta Editora, 81-125.

OliveirA, José Ferreira, 2006, As Políticas de Segurança e os Modelos de Policiamento: A Emergência do Policiamento de Proximidade. Coimbra, Nova Almedina.

PAIS, José Machado, 1996, "Levantamento bibliográfico de pesquisas sobre juventude portuguesa: tradições e mudanças (1985-1995)”, Sociologia, Problemas e Práticas, 21 : 197 -221 .

SEBASTIÃO, João, Mariana Gaio ALVES, e Joana CAMPOS, 2003, "Violência na escola: das políticas aos quotidianos", Sociologia, Problemas e Práticas, 41: 37-62.

SEBASTIÃO, João, Mariana Gaio ALVES, e Joana CAMPOS, 2010, "Violência na escola e sociedade de risco: uma aproximação ao caso português”, em João Sebastião (org.), Violência na Escola: Tendências, Contextos, Olhares. Alpiarça, Edições Cosmos, 15-43.

TILLEY, Nick, 2008, "Modern approaches to policing: community, problem-oriented and intelligence-led”, em Tim Newburn (org.), Handbook of Policing. Portland, OR, Willan Publishing, 373-403.

WACQUANT, Loïc, 2009, Punishing the Poor: The Neoliberal Government of the Poor. Durham e Londres, Duke University Press.

WESTMARLAND, Louise, 2008, "Police cultures", em Tim Newburn (org.), Handbook of Policing. Portland, OR, Willan Publishing, 253-280. 